\title{
EVALUATION OF PHYSICAL EXERCISE'S EFFECTS ON LOW BACK PAIN AMONG UNIVERSITY STUDENTS WITH SHORT FORM-36 AND OSWESTRY DISABILITY INDEX
}

\author{
Arda Ulaş Mutlu ${ }^{1}$, Bilgesu Aydın², Özge Ecertaştan ${ }^{3}$, Eren Öğüt ${ }^{4}$, Bilge Güvenç Tuna ${ }^{5}$, Hakan Tuna ${ }^{6}$ \\ ${ }^{1}$ Trakya University School of Medicine, Edirne, TURKEY \\ ${ }^{2}$ Yeditepe University School of Medicine, Istanbul, TURKEY \\ ${ }^{3}$ Bahçeşehir University School of Medicine, Istanbul, TURKEY \\ ${ }^{4}$ Department of Anatomy, Bahçeşehir University School of Medicine, Istanbul, TURKEY \\ ${ }^{5}$ Department of Biophysics, Yeditepe University School of Medicine, Istanbul, TURKEY \\ ${ }^{6}$ Department of Physical Medicine and Rehabilitation, Trakya University School of Medicine, Edirne, TURKEY
}

\begin{abstract}
Aims: This study aims to investigate the main effects of physical exercise on lower back pain with the Short Form-36 Health Survey and Oswestry Disability Index scores. Methods: University students between 18-25 years old who suffer from low back pain were enrolled in the study. Short Form-36 Health Survey and Oswestry Disability Index were used as the reference scales of lower back pain and quality of life, respectively. There are some questions in the questionnaire to scale the average comfort of the place they sleep and sit during the day, which is the result of the Personal Comfort Score. The Mann-Whitney U test was used for non-normal distributed variables. Correlation and Linear Regression were used to analyze data. SPSS 25.0 was used for all statistical analysis. Results: A total of 139 university students ( 94 females, 45 males) were included in the study. The median age was 20 years $(\mathrm{IQR}=2)$ for female students and 20 years $(\mathrm{IQR}=1)$ for male students. Oswestry Disability Index scores of female students were higher, while Short Form-36 scores were lower than the male students. Male students' physical functioning scores were higher than female students. Each one-unit increase in Personal Comfort Score is associated with an increase in the rate between the energy/fatigue (3.34 units). Body Mass Index considerably affected the pain and Oswestry Disability Score, an increase in one unit of baseline BMI upsurged the Short Form-36 pain score to 0.13 , and Oswestry disability score to 0.55 . Conclusion: In our study, Body Mass Index is found to be associated with Oswestry Disability Index and Short Form-36 score, which are used for the severity of low back pain and defining the life quality and of patients. PCS had a positive correlation between energy/fatigue. In addition, There was a positive correlation between physical exercise and general health score. Keywords: Low back pain, physical exercise, Body Mass Index, Short Form-36, Oswestry Disability Index
\end{abstract}

\section{INTRODUCTION}

Low back pain (LBP) is a condition caused by the strain of the muscles or the ligaments in the spine or caused by the compression of the nerve roots (1). It is one of the most significant primary global health conditions as it is the most common reason for limitation and loss of labor $(2,3)$. It is reported that $70-80 \%$ of the people living in Turkey suffer from LBP at least once in their lives (4). LBP is a common health problem among university students with different percentages. LBP prevalence is reported $65 \%$ among the Malaysian medical students and $38 \%$ among the dental students $(5,6)$.

Lower back pain has an enormous impact on our activities of daily living (ADL) such as walking, bending, bathing, getting dressed, or cooking. An Austrian study, including elderly patients, found an apparent association between LBP and problems in ADL (7). LBP also has an effect on the governments' economic burden on healthcare systems (8). According to Diele- 
man et al. (9), money spent on LBP and low-neck pain (LNP) has increased over the last 18 years by almost $\$ 57.2$ billion in the United States. In 2013, $\$ 87.6$ billion was spent on healthcare for LBP and LNP and made it the third-most costly health problem in 2013 (9).

Although plenty of research has been made on LBP, the leading cause of the disease remains unknown. There are many different factors thought to play a role in LBP, including body mass index (BMI), psychiatric disorders, mobility, gender, and age (10). The majority of LBP is categorized as non-specific LBP. Therefore, further research should be done to better understand the cause in order to enhance the prognostic plans used (11). Hence, analyzing the causes and results of this health condition is crucial to optimize preventive strategies, improve the overall economy, and better the quality of life. In addition, there is a lack of research done to determine the effects of routine physical exercises on $\operatorname{LBP}(12,13)$.

Many different scales have been formed to define people's life quality and physical functioning. The two commonly used ones are Short Form-36 (SF-36) and the Oswestry Disability Index (ODI) (14). The ODI is reported acceptable for measuring disabilities related to LBP by the International Forum for Primary Care Research on LBP while the SF-36 questionnaire is a health-related quality of life measurement that has been extensively used in observational studies for various conditions (15).

This study aims to investigate the effects of physical exercise on the SF-36 and ODI scores on university students at the age of 18-25 experiencing LBP. For this purpose, differences between physical functioning and gender; energy and Personal Comfort Score (PCS); pain and gender; general health and weekly exercise time; pain and BMI; ODI score and BMI were compared among the university students with the age of 18-25 from three different universities in Turkey.

\section{MATERIAL AND METHODS}

This study was approved by the Scientific Research Ethical Committee of Trakya University School of Medicine (Protocol Code: TÜTF-BAEK2019/471). Participants' informed consents were taken online in written format before filling the questionnaire. Data were collected from the students from Trakya University, Bahçeşehir University and Yeditepe University from October 2019 to January 2020. The online questionnaire form was distributed to universities. The main group of the study was 18-25 years old university students who suffer from LBP. One hundred forty-four participants completed the whole online questionnaires, which include age, sex, alcohol/smoking/drugs addiction, university, year at the university, number of steps per day, hours of sleep per night, PCS which is attained by the questions about the comfort of the accommodation and sleep, hours of physical exercise per week, comorbidities, LBP levels, SF-36 and ODI tests, weight, and height (BMI). Exclusion criteria include factors such as the age of students, stage of the disease, the subject's previous treatment history, and the presence of any psychosocial and emotional conditions. Therefore, five students were excluded from the present study, related to the orthopaedical disabilities (arthritis, fractures, scoliosis) and the questionnaires with invalid responses. In the end, a total of 139 university students (94 females, 45 males) were included in the study.

Turkish versions of SF-36 and ODI were used as the reference scales for quality of life and pain. Validations of these scales were researched in advance $(16,17)$. ODI is a test composed of 10 questions and it is scored between $0-5$. In order to find the ODI score, the values of the participants' answers are summed then doubled. Score zero corresponds to no disability, while score 5 corresponds to maximum possible disability (18). SF36 is a test with 36 questions scored between $0-100$. Every subheading is scored by the average of relevant questions from the test. ODI was evaluated with one final score, and SF-36 was evaluated with eight different scores being: physical functioning, role limitations due to physical health, role limitations due to emotional problems, energy/fatigue, emotional well-being, social functioning, pain, and general health. PCS is the average comfort of the places where they sleep and sit during the day. Scaling of PCS is between 0 - 10, which selecting 0 means least comfortable, and selecting 10 means the most comfortable place. Weekly exercise time as the hour was used to evaluate the physical exercise $(16,17)$.

Statistical Package for the Social Sciences (SPSS) version 25 was used to analyze the data. The Kolmogorov-Smirnov test was used as a test of normality. Descriptive statistics of continuous variables (age, BMI, PCS, weekly physical exercise time, numbers of step per day, physical functioning, physical role functioning score, emotional role functioning score, energy/fatigue score, emotional well-being score, social functioning score, pain score, general health score and ODI score) were given as median and IQR. Since all of the aforementioned variables were distrubted non-normally, Mann-Whitney U test was used to compare the data. Categorical data (gender, universities and participants' grades) were presented as numbers 
(n) and percentages (\%). Correlation between BMI, numbers of step per day, ODI Score, SF-36 subheadings, PCS and weekly exercise time were analyzed.

Differences between ODI score and gender and SF-36 subheadings' scores and gender were analyzed by Mann-Whitney $U$ test. ODI score and age; SF36 subheadings' scores and age; ODI score and PCS; SF-36 subheadings' scores and PCS; ODI score and weekly exercise time; SF-36 subheadings' scores and weekly exercise time; ODI score and BMI: SF-36 subheadings' scores and BMI; ODI score and average daily steps; SF-36 subheadings' scores and average daily steps; ODI score and daily studying time; SF-36 subheadings' scores and daily studying time were analyzed by univariate linear regression tests. (ODI score and SF36 subheadings' scores are dependent variables whereas age, PCS, weekly exercise time, BMI, average daily steps, and daily studying time are independent variables. The residuals of the regression follow normal distribution.) For all statistical comparisons, $\mathrm{p}<0.05$ was assumed to indicate statistical significance.

\section{RESULTS}

In total, the responses of 139 students were included in this study. There were 94 (67.63\%) female students, and $45(32.37 \%)$ male students. Their median age was 20 years. Descriptive statistics of the participants are shown in Table 1. Most of the students were from Trakya University (60.43\%), and the least was from Bahçeşehir University (10.8\%) (Table 2). Participants were from six different grades, and the number of participants was decreasing in every grade (Table 3 ).

The median age of participants was 20 years for females and 20 years for males. The age difference between gender groups was not statistically significant $(\mathrm{p}=0.854)$. Median BMI's of participants was calculated as 20.45 for females and 24.45 for males. Differences between groups were statistically significant $(\mathrm{p}<0.001)$. Median PCS's were calculated as 6.66 for females and 7 for males. Differences between groups were not statistically significant $(\mathrm{p}=0.453)$. Medians of weekly exercise time in hours were calculated as 2.5 for the female group and 5 for the male group. Differences in median levels of groups were statistically significant $(\mathrm{p}<0.001)$. The median of daily steps was 7000 for the female group and 8000 for the male group. Differences between groups were not statistically significant $(\mathrm{p}=0.109)$. Median levels of physical role functioning, emotional role functioning, energy /fatigue, emotional well-being, social functioning and general health between two genders weren't statistically significant $(\mathrm{p}=0.824, \mathrm{p}=0.981, \mathrm{p}=0.11, \mathrm{p}=0.338$, $\mathrm{p}=0.177, \mathrm{p}=0.13$, respectively). Differences in median levels of physical functioning, pain, and ODI sco-

\section{Table 1: Universities of participants.}

\section{Numbers (n) / Percentage (\%)}

$\begin{array}{ll}\text { Trakya University } & 84(60.43 \%) \\ \text { Yeditepe University } & 40(28.77 \%) \\ \text { Bahçeșehir University } & 15(10.8 \%)\end{array}$

Table 2: University grades of the participants.

\begin{tabular}{ll} 
& $\begin{array}{l}\text { Numbers (n)/ } \\
\text { Percentage (\%) }\end{array}$ \\
\hline $1^{\text {st }}$ Grade & $48(34.53 \%)$ \\
$2^{\text {nd }}$ Grade & $43(30.94)$ \\
$3^{\text {rd }}$ Grade & $17(12.23 \%)$ \\
$4^{\text {th }}$ Grade & $18(12.95 \%)$ \\
$5^{\text {th }}$ Grade & $9(6.47 \%)$ \\
$6^{\text {th }}$ Grade & $4(2.88 \%)$ \\
\hline
\end{tabular}


Table 3: Comparison of parameters by gender.

\begin{tabular}{|c|c|c|c|c|}
\hline & $\begin{array}{l}\text { Female [median } \\
(I Q R)]\end{array}$ & $\begin{array}{l}\text { Male [median } \\
(I Q R)]\end{array}$ & p-value & Total Median (IQR) \\
\hline Age (years) & $20(2)$ & $20(1)$ & 0.854 & $20(1)$ \\
\hline$B M I^{*}\left(k g / m^{2}\right)$ & $20.45(3.73)$ & $24.45(4.6)$ & $<0.001$ & $21.09(5.66)$ \\
\hline PCS & $6.66(1.33)$ & $7(1)$ & 0.453 & $6.67(1.33)$ \\
\hline Physical & $2.5(3)$ & $5(5)$ & $<0.001$ & $3(4)$ \\
\hline \multicolumn{5}{|l|}{$\begin{array}{l}\text { Exercise } \\
\text { (h/week) }\end{array}$} \\
\hline $\begin{array}{l}\text { Number of } \\
\text { Steps per Day }\end{array}$ & $7000(4000)$ & $8000(4000)$ & 0.109 & $7000(3000)$ \\
\hline Physical & $90(16.25)$ & $100(10)$ & $<0.001$ & $95(15)$ \\
\hline \multicolumn{5}{|l|}{ Functioning } \\
\hline Role & $75(75)$ & $75(75)$ & 0.824 & $75(75)$ \\
\hline \multicolumn{5}{|l|}{$\begin{array}{l}\text { Functioning / } \\
\text { Physical }\end{array}$} \\
\hline Role & $33.33(33.33)$ & $33.33(83.33)$ & 0.981 & $33.3(66.6)$ \\
\hline \multicolumn{5}{|l|}{$\begin{array}{l}\text { Functioning / } \\
\text { Emotional }\end{array}$} \\
\hline $\begin{array}{l}\text { Energy / } \\
\text { Fatigue }\end{array}$ & $50(30)$ & $50(25)$ & 0.11 & $50(30)$ \\
\hline $\begin{array}{l}\text { Emotional } \\
\text { Well-Being }\end{array}$ & $56(32)$ & $60(22)$ & 0.338 & $56(24)$ \\
\hline $\begin{array}{l}\text { Social } \\
\text { Functioning }\end{array}$ & $62.5(32.5)$ & $87.5(32.5)$ & 0.177 & $75(37.5)$ \\
\hline Pain & $77.5(27.5)$ & $90(32.5)$ & 0.001 & $77.5(27.5)$ \\
\hline General & $60(30)$ & $65(25)$ & 0.13 & $60(25)$ \\
\hline Health & & & & \\
\hline ODI (\%) & $12(16)$ & $8(17)$ & 0.028 & $12(17.5)$ \\
\hline & & & & Male $=45(32.37 \%)$ \\
\hline
\end{tabular}

[number (\%)]

Female $=94(67.63 \%)$

BMI: Body Mass Index, PCS: Personal Comfort Score, ODI: Oswestry Disability Index. Independent samples test ${ }^{*}$ Mann Whitney U Test

res between two genders were statistically significant ( $\mathrm{p}<0.001, \mathrm{p}=0.001, \mathrm{p}=0.028$, respectively) (Table 4 ).

The results of our study revealed that the collected data from female participants had a negative correlation between physical functioning and pain scores for SF-36 ( $\mathrm{r}=-0.4325) \quad(\mathrm{p}=0.839)$. Male participants' physical functioning scores were 5.98 units higher than females', and also their pain scores were 10.58 unit higher than females' $(\mathrm{p}=0.024, \mathrm{p}=0.002$, respectively). Every 1 unit increase in PCS is associated with 3.34 units increase in the rate between the energy/fatigue $(r=0.1844, p=0.03)$. Each hour of physical exer- cise increases the general health score with 1.10 units $(\mathrm{r}=0.2067, \mathrm{p}=0.015)$. Our results showed that BMI considerably affects the pain and ODI score numerically positive. With every increment in BMI baseline, SF36 pain score increases by 0.13 and ODI score by 0.55 $(\mathrm{r}=0.1033, \mathrm{p}=0.048 ; \mathrm{r}=0.1113, \mathrm{p}=0.04$, respectively).

There was no significant difference found in ODI and age; SF-36 subheadings' scores and age; ODI and PCS; ODI and weekly exercise time; ODI and number of steps per day; SF-36 subheadings' scores and number of steps per day; ODI and daily studying time; SF-36 subheadings' scores and daily studying time between genders. 


\section{DISCUSSION}

Lower back pain is a general and serious discomfort between university students. The present study showed that BMI was a factor affecting ODI and SF-36 scores, which are used to define life quality and LBP seriousness. This study revealed that the comfort of places we sit and sleep during the day, PCS, had a positive correlation with energy/fatigue. This finding may indicate that when PCS is increased, energy increases whereas fatigue decreases, as expected. In addition, there was a positive correlation between physical exercise and general health score. Since gender is a non-modifiable risk factor for LBP, improving modifiable factors such as exercise and PCS may play a major role in increasing the quality of life and decreasing LBP.

In this study, life quality and LBP were evaluated thorough ODI and SF-36. It is found that ODI and SF36 are affected by BMI. SF-36 contains eight domain scores, including "physical functioning" (19-21). This domain asks respondents about limitations on their mobility activities. Musculoskeletal pain (MSP), which also includes LBP is a health problem seen in the adolescent population at a rate of $4-40 \%$ (22). In the study of Guite et al. (23), it has been shown that MSP affects overall life quality by causing physical disability. In their study, the mean age (15 \pm 1.4 years) was lower than our study. They used The Functional Disability Inventory instead of ODI and The Self-Perception Profile for Adolescents instead of SF-36 (23). In spite of having the similar result about muscle pain's effects, the aims of these two studies had a major difference; our study was aiming to reveal the factors that may be related to LBP, whilst the prementioned study was aiming to reveal the results of MSP. Our study revealed a positive correlation between the life quality and physical exercise in one subheading of SF-36, general health. In the other seven subheadings, our study demonstrated that the correlation between life quality and physical exercise was not statistically significant.

Our study showed that the comfort of places we sit and sleep during the day, PCS, affects our overall energy and fatigue during the day. Some studies stated that fatigue is related to age and gender $(24,25)$, wheras in our study, there was not any significant difference between genders or age in the ratio of energy/fatigue; it may possibly be due to the age limitation. Our participants were aged between 18 and 25, but the prementioned studies had different limitations, such as $25-74$ years. Fatigue is also one of the reasons and symptoms of major depression (25). According to these studies, older people, especially females, had 1.5 times more possible to experience fatigue $(24,25)$. Therefore, the discomfort of the places we sit, and sleep may increase the risk of experiencing fatigue. This may play a role in the onset of depression.. In a study done by Corfield et al. (26), out of $10.5 \%$ depressed people, $63.8 \%$ of them experienced fatigue. In addition, depression is intercorrelated with fatigue. Whilst fatigued people feel more depressed, depressed people feel more fatigue.

Amelot et al. (27) collected information related to a regular exercise routine and type and indicated that regular physical activity decreases LBP occurrence. Although we have only asked weekly exercise time of participants instead of their routine and the type of exercise, we have similar results. Our results showed that there was also a correlation between general health and weekly exercise time. In addition to this finding, Amelot et al. (27) stated that there is a correlation between LBP and gender and LBP has an impact on personal schoolwork, personal life, personal social activities and quality of sleep in 1243 participants. Similarly, the present study revealed a positive correlation between physical functioning and gender in 139 participants.

Muntaner-Mas et al. (28) claimed there was not a significant correlation between the participants in sports and LBP. According to Muntaner-Mas et al. (28), females had more severe LBP than male participants. In our study, SF-36 scores of females were lower than male students, but ODI scores were higher than male participants. Female participants of our study had more severe LBP than males due to the differences in the physical development of participants, daily activities, numbers, and mean age of participants.

Some limitations were recorded in the study. Since the questionnaire was distributed online, the participants did not have a chance to communicate with researchers directly and to overcome misunderstandings. The other limitation was the number of participants. More than 3000 students were contacted, but only 144 have been recorded in the study.

In conclusion, LBP is a common medical problem among university students. Our study showed that there are various factors affecting students' lives positively or negatively according to participants' SF-36 and ODI scores. PCS had a positive correlation between energy/fatigue. In addition, There was a positive correlation between physical exercise and general health score. Students may modify their weekly exercise time and comfort of the places they sit and sleep to increase their own life quality and decrease the problems they face due to LBP. However, further studies are needed in order to elucidate the major causes of LBP. 
Ethics Committee Approval: This study was approved by the Scientific Research Ethical Committee of Trakya University School of Medicine (Protocol Code: TÜTF-BAEK2019/471).

Informed Consent: Written informed consent was obtained from the participants of this study.

Conflict of Interest: The authors declared no conflict of interest.

Author contributions: Concept: AUM, BA, ÖE, EÖ, BGT, HT Design: AUM, BA, ÖE, EÖ, BGT, HT Supervision: AUM, BA, ÖE, EÖ, BGT, HT Resources: AUM, BA, ÖE, EÖ, BGT, HT Materials: AUM, BA, ÖE, EÖ, BGT, HT Data collection and/or processing: AUM, BA, ÖE, EÖ, BGT, HT Analysis and/or Interpretation: AUM, BA, ÖE, EÖ, BGT, HT Literature Search:AUM, BA, ÖE, EÖ, BGT, HT Writing Manuscript: AUM, BA, ÖE, EÖ, BGT, HT Critical Review: AUM, BA, ÖE, EÖ, BGT, HT.

Financial disclosure: The authors declared that this study received no financial support.

Editor in chief's Note: One author of this article, Arda Ulaş Mutlu is a members of the editorial board of Turkish Medical Student Journal. However, he did not take place in any stage of the editorial decision of the manuscript. The editors who evaluated this manuscript are from other institutions.

\section{REFERENCES}

1. Gökmen FG, Ertürk M. Hareket Sistemi/Kemikler. Sistematik Anatomi. İzmir: Güven Kitabevi; 2003.

2. Hoy D, March L, Brooks P et al. The global burden of low back pain: estimates from the global burden of disease 2010 study. Ann Rheum Dis 2014;73(6):968-74.

3. Lidgren L. The bone and joint decade 2000-2010. Bull World Health Organ 2003;81(9):629.

4. Özcan Yıldız E. Bel Ağrısı. Fiziksel Tip ve Rehabilitasyon. Ankara: Güneș Kitabevi; 2000.

5. Hayes MJ, Smith DR, Cockrell D. Prevalence and correlates of musculoskeletal disorders among Australian dental hygiene students. Int J Dent Hyg 2009;7:176 - 81.

6. Alshagga MA, Nimer AR, Yan LP et al. Prevalence and factors associated with neck, shoulder and low back pains among medical students in a Malaysian Medical College. BMC Res Notes 2013;6:244. 7. Stamm TA, Pieber K, Crevenna R et al. Impairment in the activities of daily living in older adults with and without osteoporosis, osteoarthritis and chronic back pain: a secondary analysis of population-based health survey data. BMC Musculoskeletal Disorders 2016;17(1):139.

8. Thelin A, Holmberg S, Thelin N. Functioning in the neck and low back pain from a 12-year perspective: a prospective population-based study. Journal of Rehabilitation Medicine 2008;40(7):555-61.

9. Dieleman JL, Baral R, Birger M et al. US spending on personal health care and public health 1996-2013. JAMA 2016;316(24):2627-46. 10. Vujcic I, Stojilovic N, Dubljanin E et al. Low Back Pain among medical students in Belgrade (Serbia): a cross-sectional study. Pain
Res Manag 2018;6:8317906.

11. Croft P, Altman DG, Deeks JJ et al. The science of clinical practise: disease diagnosis or patient prognosis? Evidence about "what is likely to happen" should shape clinical practice. BMC Med 2015;(30):13.

12. Guralnik JM, Ferrucci L, Pieper CF et al. Lower extremity function and subsequent disability: consistency across studies, predictive models, and value of gait speed alone compared with the short physical performance battery. J Gerontol A Biol Sci Med Sci 2000;55:22131.

13. Ostir GV, Markides KS, Black SA et al. Lower body functioning as a predictor of subsequent disability among older Mexican Americans. J Gerontol A Biol Sci Med Sci 1998;53:491-5.

14. Andresen EM, Gravitt GW, Aydelotte ME et al. Limitations of the SF-36 in a sample of nursing home residents. Age and Ageing 1999;28:562-6.

15. Ware JE Jr, Gandek B. Overview of the SF-36 Health Survey and the International Quality of Life Assessment (IQOLA) Project. J Clin Epidemiol 1998;51:903-12.

16. Koçyiğit H, Aydemir O, Fişek G et al. Reliability and Validity of the Turkish Version of Short Form-36 (SF-36). İlaç ve Tedavi Dergisi 1999;12:102-6.

17. Yakut E, Düger T, Öksüz Ç et al. Validation of the Turkish version of the Oswestry Disability Index for patients with low back pain. Spine 2004;29(5):581-5.

18. Fairbank JC, Couper J, Davies JB. The Oswestry Low Back Pain Questionnaire. Physiotherapy 1980;66:271-3.

19. Prescott-Clarke P, Primatesta P. Health Survey for England 1999. London;2000.

20. Ferrucci L, Guralnik JM, Studenski S et al. Designing randomized, controlled trials aimed at preventing or delaying functional decline and disability in frail, older persons: a consensus report. J Am Geriatr Soc 2004;52:625-34.

21. Brazier JE, Harper R, Jones NM et al. Validating the SF-36 health survey questionnaire: new outcome measure for primary care. BMJ, 1992;305:160-4.

22. Tanaka M, Fukuda S, Mizuno K et al. Stress and coping styles are associated with severe fatigue in medical students, Behavioral Medicine 2009;35(3):87-92.

23. Guite JW, Logan DE, Sherry DD et al. Adolescent self-perception: associations with chronic musculoskeletal pain and functional disability. J Pain 2007;8(5):379-86.

24. Moroder P, Runer A, Resch H et al. Low back pain among medical students. Acta Orthopaedica Belgica 2011;77(1):88-92.

25. Chen MK. The epidemiology of self-perceived fatigue among adults. Prev Med 1986;15:74-81.

26. Corfield EC, Martin NG, Nyholt DR. Co-occurrence and symptomatology of fatigue and depression. Compr Psychiatry, 2016;71:1-10. 27. Amelot A, Mathon B, Haddad R et al. Low back pain among medical students. SPINE 2019;44(19):1390-5.

28. Muntaner-Mas A, Palou P, Ortega FP et al. Sports participation and low back pain in schoolchildren. Journal of Back and Musculoskeletal Rehabilitation 2018;1:1-9. 